\title{
The African Origin of Complex Projectile Technology: An Analysis Using Tip Cross-Sectional Area and Perimeter
}

\author{
Matthew L. Sisk ${ }^{1}$ and John J. Shea ${ }^{2}$ \\ ${ }^{1}$ Interdepartmental Doctoral Program in Anthropological Sciences, Stony Brook University, Stony Brook, NY 11794-4364, USA \\ ${ }^{2}$ Department of Anthropology, Stony Brook University, Stony Brook, NY 11794-4364, USA
}

Correspondence should be addressed to Matthew L.Sisk, matthew.sisk@stonybrook.edu

Received 15 September 2010; Accepted 31 January 2011

Academic Editor: John Gowlett

Copyright (C) 2011 M. L. Sisk and J. J. Shea. This is an open access article distributed under the Creative Commons Attribution License, which permits unrestricted use, distribution, and reproduction in any medium, provided the original work is properly cited.

\begin{abstract}
Despite a body of literature focusing on the functionality of modern and stylistically distinct projectile points, comparatively little attention has been paid to quantifying the functionality of the early stages of projectile use. Previous work identified a simple ballistics measure, the Tip Cross-Sectional Area, as a way of determining if a given class of stone points could have served as effective projectile armatures. Here we use this in combination with an alternate measure, the Tip Cross-Sectional Perimeter, a more accurate proxy of the force needed to penetrate a target to a lethal depth. The current study discusses this measure and uses it to analyze a collection of measurements from African Middle Stone Age pointed stone artifacts. Several point types that were rejected in previous studies are statistically indistinguishable from ethnographic projectile points using this new measure. The ramifications of this finding for a Middle Stone Age origin of complex projectile technology is discussed.
\end{abstract}

\section{Introduction}

Recent fossil discoveries and genetic analyses indicate that Homo sapiens evolved in Africa by at least 200 thousand years ago (ka) $[1,2]$. From this point until the present there are two very different patterns in both geographic range and behavior. Until 50 thousand years ago, Homo sapiens remained endemic to Africa with only a brief expansion into the contiguous Levantine corridor [3, 4]. Around $50 \mathrm{ka}$, there is considerable evidence for a dispersal that expanded the range of Homo sapiens throughout the Old World [5-8]. Absolute dates for this dispersal vary considerably, though most fall in the range of $60 \mathrm{ka}$ to $35 \mathrm{ka}$ (e.g., $[9,10])$. Most researchers agree, however, that following this dispersal, Homo sapiens fossils are associated with a material culture more closely resembling that of ethnographic hunter-gatherers than that of previous hominins [11-13]. Thus, this dispersal has long been thought to mark a behavioral "revolution" or a significant shift to more complex behaviors unique to Homo sapiens. These complex behaviors may include the production of labor-intensive stone, antler and bone tools, the transfer of raw materials across long distances, the creation of a wide variety of personal adornments and other symbolic objects, and the development of more complex subsistence behaviors (i.e., broad-spectrum foraging and specialized big game hunting). The mode and tempo of this dispersal are hotly debated topics in paleoanthropology (e.g., $[4,11,14])$, but it is generally assumed that these novel behavioral adaptations played an important role.

Traditionally, these post-50 ka behavioral changes have been viewed as part of a single process: the evolution of "modern" human behavior. However, there is evidence for the presence of some of these components earlier in the African Middle Stone Age (MSA) [11]. Furthermore, there is no compelling reason to assume synchronicity in all of these components [15]. An adaptive shift that resulted in specialized hunting would not necessarily also cause the development of personal adornments, although synergy between these, and all factors, remains a possibility. Thus, while some researchers still view this change holistically, as a single watershed event (e.g., [4]), many others have turned to investigating the sources and results of adaptive shifts analytically in terms of particular component behaviors (e.g., [15-17]). In particular, one of the most striking aspects of 
the Homo sapiens adaptation after $50 \mathrm{ka}$ is the occupation of a wide variety of environments. Thus, in attempting to understand the evolutionarily significant behavioral changes that led to the success of Homo sapiens, special attention should be paid to those adaptations that increase ecological versatility among recent human populations.

Complex projectile technology is one such adaptation. Complex projectiles, like the bow/arrow or spearthrower/dart, are composite technologies that propel a high velocity projectile by storing or enhancing energy in a nonprojectile component $[18,19]$. Simple projectile weapons, in contrast, are those that rely solely on human mechanical energy for propulsion, like hand-cast spears, javelins, and throwing sticks. Complex projectile technology is a universal part of contemporary human adaptations, found among societies ranging from hunter-gatherer bands to industrial states, indicating that these technologies confer a significant ecological advantage. Furthermore, living human groups use projectiles to hunt prey of dramatically differing sizes and in diverse habitats, ranging from arctic deserts to tropical rainforests $[20,21]$. Thus, these technologies increase hunting versatility and allow the construction of a wider ecological niche.

The development and widespread use of complex projectile technologies undoubtedly marks an important transformation in the adaptation of Homo sapiens. Their origin is definitively Pleistocene [22], and they likely contributed to the success of the $50 \mathrm{ka}$ expansion of Homo sapiens into western Eurasia $[18,23]$. However, the origin and nature of early projectiles remains an enigma.

While simple projectile weapons, like javelins, have been found in Lower and Middle Paleolithic contexts [24, 25], the oldest definitive complex projectile weapons date to relatively late in the Paleolithic [26]. Most of the materials used in the manufacture of complex projectile weapons, such as wood, cordage and sinew, are highly perishable. It is generally assumed that these technologies predate their oldest known examples, but how widely and for how long remain points of dispute. Despite issues of preservation, the use of complex projectile weapons can still be inferred from more durable materials. In several cases, microwear and residue analyses have suggested at least simple projectile use (i.e., hand-cast spears with stone tips) in the Middle Paleolithic/Middle Stone Age (e.g., [27-30]). Yet, such microwear and residue traces preserve only rarely, and the time-consuming process of detecting them limits analysis to small judgmental samples. Rough similarities in the form of Paleolithic points and stone projectile points of ethnographic or recent historical groups can also give some indication of projectile use [31,32] but care must be taken when forming an analogy between modern and ancient behaviors or technologies based on gross similarity. Recent projectile points, especially those in museum collections, are often heavily retouched into a specific form. These forms are often thought to serve as stylistic markers for the group [33, 34], although the chronological controls of these markers remains somewhat contentious [35-38]. Given that the interplay of stylistic and functional variation in recent and ethnographic point forms is not fully understood, it is clear that gross similarity in form cannot be directly used to compare points from time periods like the Paleolithic, where cultural associations are unknown.

Furthermore, experimental work has demonstrated that unretouched, minimally retouched [39, 40], and even wooden points [41, 42] function adequately as projectile armatures. This suggests a possibility that some strategies involving the use of complex projectile technologies may evade archaeological detection except in cases of extraordinary preservation (e.g., waterlogging, freezing, or dessication). While there may be some functional advantage in crafting the perfect projectile point, the advantages must have been weighed against the "costs" of time and effort. Thus, it is important for researchers to look not only at the particular forms of recent projectile points as guides to recognize ancient examples, but also at ballistically significant metrics derived from ethnographic and experimental data.

1.1. Approaches Using the Metrics of Stone Points. Thus, many researchers have begun to use such ballistically significant measurements in determining if a given class of Paleolithic points was functionally capable of serving as projectile armature (e.g., [23, 41, 43, 44]). Using measures like the weight, convergence angle, or cross-sectional area, these studies have demonstrated the potential systematic or occasional projectile use of certain tool types. It should be stressed that these studies, including the current one, only comment on potentiality. Metrics that resemble modern projectiles could be the result of a different technological adaptation for small, pointed pieces. No single measure can or should be used as a definitive test of projectile usage. Regardless, studies like these are necessary first steps in investigating Paleolithic projectile use. At the very least, metric comparisons of known projectile points to prehistoric tools of unknown function can help archaeologists prioritize samples of the latter artifacts for more diagnostic studies employing microwear, breakage, and residue analysis.

One factor that limits the utility of metric analyses is our current understanding of factors influencing projectile penetration in prehistoric technological contexts. Ballistics measures are typically applied to, and derived from, firearms or high-powered bows with metal tips. Thus, these may not be accurate when applied to technologies available in the Paleolithic. Experimental studies (e.g., $[40,45,46])$ that have tested the accuracy of these measurements generally show that while simple measures may serve as a proxy, they may also be biased towards certain forms. As experimental work continues to untangle the penetration efficiency of stone points propelled by different technologies and at various ranges, it is vital that models of Paleolithic projectile use are updated as our knowledge of these measurements grows.

1.2. Tip Cross-Sectional Area and Perimeter. Most important among these ballistic measurements is the tip cross-sectional area (TCSA) [23, 47, 48]. The TCSA should represent the force necessary to penetrate a target to a lethal depth. Thus, the larger the TCSA, the more force that is needed. As a mechanical rather than a stylistic constraint, Shea [23] argued that the TCSA of a given artifact type should 


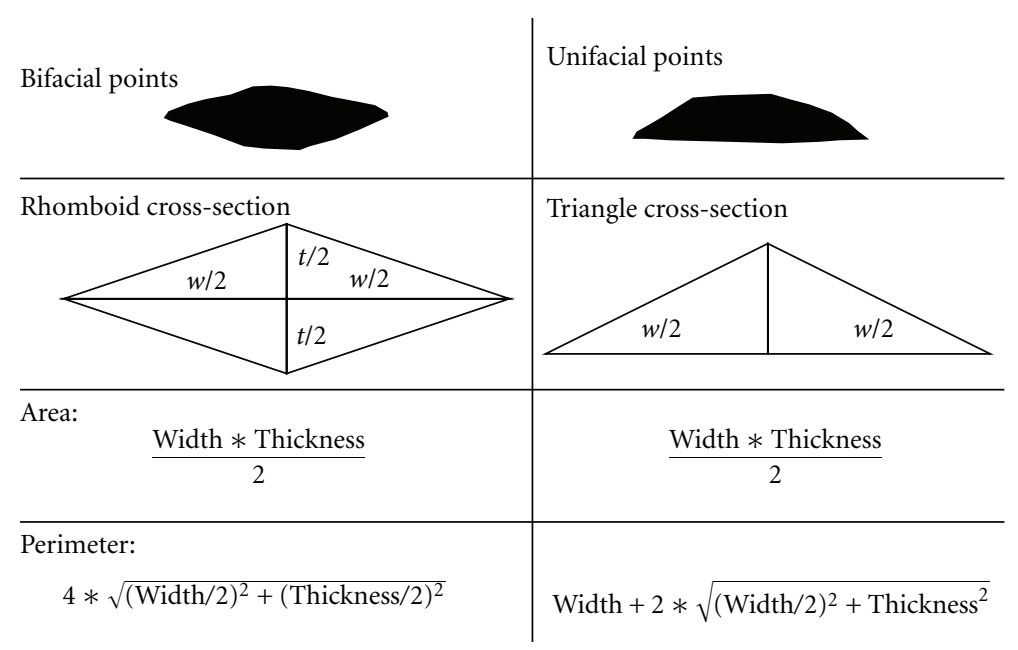

Figure 1: Comparison of two different estimates of the cross-section of stone points. The rhomboid measure more accurately estimates bifacially worked points while the triangular measure is most accurate for unifacial or unretouched points.

have a central tendency that resembles ethnographic or experimental projectile points in order to be considered a plausible projectile armature. TCSA also has the advantage of being an easy calculation, requiring only the maximum width and thickness of a stone point.

Previous work has shown a clear separation in the TCSA of different projectile types (bow/arrow, spearthrower/dart, throwing spears) resulting from effective force and the characteristics of the technology $[40,45,47]$. The TCSA of archaeological points can then be compared to collections of hafted ethnographic arrowheads and dart-tips to give an idea of the projectile technology for which they were designed $[23,47,48]$. Artifacts with TCSA values that resemble ethnographic projectile points may then be interpreted as potential effective projectile armatures. In particular, Shea [23] applied this measure to samples of points from Africa, Southwest Asia and Europe to show when the earliest plausible stone projectile points occur in these regions. In this study, points that were statistically indistinguishable from ethnographic projectiles were only found in the Upper Paleolithic and the Late Stone Age (younger than $40 \mathrm{ka}$ ). This finding does not support a hypothesis of earlier projectile use, although it is noted that nonsystematic or occasional use would likely go undetected [23]. A further complicating factor arises from archaeologists' practice of grouping stone tools of widely varying sizes together into the same artifact type. This practice can result in plausible projectile points, which are usually relatively small, passing undetected among large numbers of very large points.

Initial experimental work supports the utility of TCSA as acceptable proxy for potential projectile use [40, 45]. However, its utility may actually derive from the fact that it tracks another measure, the tip cross-sectional perimeter (TCSP). Measures from ballistics, like TCSA, predict a case where the projectile, such as a bullet, pulverizes the target. This makes the area an important predictor of the size of the hole, which is then used as a proxy for the energy needed to penetrate to a lethal depth. Stone points instead work by effectively slicing a hole in the target. In this case, the size of the hole is controlled by the point's outer margin or its perimeter, rather than by the area [40].

Both TCSA and TCSP are composed of the same measurements, maximum thickness and width, so in all cases they should be very highly correlated. Therefore, previous trends isolated by comparing TCSA values are likely accurate, but they may result from tracking variation in TCSP rather than from the analytic power of TCSA.

There are some limitations to using TCSP analytically. In particular, the perimeter measure is more sensitive to shape differences [40, 47]. Many modern ethnographic projectile points are bifacially retouched, yielding a roughly rhomboid or biconvex cross-section. However, simple pointed flakes have a cross-section more accurately represented by a triangle or trapezoid (Figure 1). When modeling the cross-section of a point, one of these estimates must be chosen. For the area, the calculation is the same in either case, but for the perimeter, these two estimates result in different values (Figure 1). However, because using the triangular measure increases the perimeter, it actually reduces the likelihood that a given class will be grouped with bifacial ethnographic arrowheads and dart tips (Figure 2) and is thus, in some ways, a more restrictive measure.

\section{Methods}

This analysis uses TCSP on pointed artifacts from African MSA contexts. To directly compare the results of a TCSP measure to a known TCSA-based study, it utilizes the same dataset of lithic point measurements used in Shea's [23] analysis of TCSA across the Paleolithic Old World. Because the current analysis is primarily concerned with the potential African origins of complex projectile technology, only the point classes from the African Middle Stone Age are included ( $n=1863$; see Table 1$)$. It should be noted that, in a few cases, the total number of artifacts in each sample is slightly 


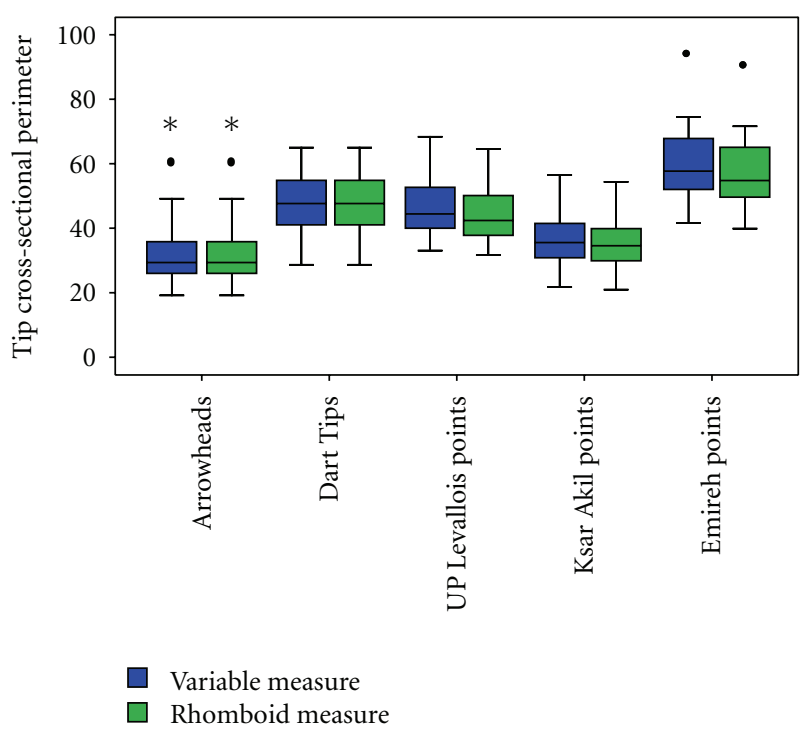

FIgUre 2: Comparison of the TCSP estimates using the rhomboid measure for all and using the triangular estimate for unifacial points.

less than that of Shea [23]. This is due to the removal of point measurements that, upon reexamination, appear to be duplicates or otherwise questionable.

These points were compared to the same ethnographic control samples as the previous analysis [23]. These include a collection of 118 arrowheads and 10 spearthrower dart tips from of the American Museum of Natural History measured by Thomas [49] and 30 dart tips from various other museums measured by Shott [50]. Summary data for all of these points are reported in Table 1. In this study, we do not include the comparative sample of experimental thrusting spear points used by Shea [23]. This sample was excluded both because of our focus on complex projectiles and because this experimental sample may not represent the actual variability in this technology. We instead assume that TCSA or TCSP values exceeding those of the ethnographic sample are outside the functional threshold of complex projectiles.

The MSA point dataset contains both bifacially and unifacially worked types, so both the triangular and rhomboid measures were used. The ethnographic arrow and dart comparison sample are all classified as bifacially worked and the perimeter estimated as a rhombus. This difference in the calculation of values for both the archaeological and comparative sample may introduce error into the analyses. Therefore, all analyses were conducted twice, once with the variable perimeter estimation and once with all perimeters estimated by the rhomboid measure.

\section{Results}

As discussed above, the triangular estimation results in a larger perimeter measure. This then reduces the likelihood of a triangular point type being classified with the bifacial ethnographic controls. Therefore, the analysis using the rhomboid estimation for all points will be discussed only in cases where the estimation changes the grouping. All data, including which estimation was used for the variable measure, are reported in Table 2.

Figures 3 and 4 show box and whisker plots for the TCSA and TCSP estimations of the ethnographic arrowhead and dart tips and each of the MSA point types. The upper and lower quartiles of each ethnographic class are highlighted to illustrate any overlap between these and the MSA point types. The TCSA measure shows the dart tips' upper and lower quartile area overlapping with those both types of points from Porc Epic and some of the subsamples of Aterian points. The TCSP shows overlap between the upper and lower quartiles of the dart tips and all MSA point samples except the three Klassies River Mouth samples and one of the Aterian subsamples.

Table 2 reports a series of independent sample $t$-tests comparing each of the artifact types to the ethnographic arrowhead and dart tip samples. All of the MSA types were larger in both TCSA and TCSP than ethnographic arrowheads at a high level of significance $(p<.0001)$. As reported in Shea [23], all MSA TCSA values are also significantly greater than the ethnographic dart tips $(p<$ $.05)$. However, in several cases, the TCSP measures for the MSA points fell within the variation of the dart-tips. These include bifacially worked points from Porc Epic and two samples of Aterian points (from Aoulef and Azrag). Additionally, if the rhomboid estimation for TCSP is applied to the unifacial points from Porc Epic, these also fall within the variation of modern dart tips.

\section{Discussion}

As previously noted [40], TCSP appears to be an accurate proxy for projectile effectiveness. From this study of African Middle Stone Age points it is apparent that the TCSP follows a pattern similar to what previous studies found for the TCSA. However, where previous work identified trends in the TCSA, this study found several samples of MSA points that are statistically indistinguishable from ethnographic dart tips. While in some cases this could be the result of small sample size (e.g., the Aterian points from Aoulef), other types are more conclusively similar to dart tips (e.g., bifacial points from Porc Epic). A comparison of the box and whisker plots also qualitatively illustrates that there is more overlap in TCSP between the ethnographic and MSA archaeological samples. This indicates that at least some classes of Middle Stone Age points could have served as effective projectiles. This result also raises the possibility of ancient spearthrower use in Africa, expanding the geographic range of this weapon system significantly beyond its known ethnographic occurrence.

The types of MSA points that fall within ethnographic point variation also yield some interesting results. In particular, if typological classifications accurately reflect use, one would expect all Aterian points to yield a similar statistical pattern. Here, two subsets of the Aterian sample fell within the range of ethnographic dart-tips and two, and the lumped sample, were significantly larger. This would seem to indicate 
TABLE 1: Summary statistics and information for the control and MSA samples.

\begin{tabular}{|c|c|c|c|c|c|c|c|}
\hline \multirow{2}{*}{ Industry } & \multirow{2}{*}{$N$} & \multicolumn{2}{|c|}{ Width } & \multicolumn{2}{|c|}{ Thickness } & \multirow{2}{*}{$\begin{array}{l}\text { Cross-section } \\
\text { estimate }\end{array}$} & \multirow{2}{*}{ Source } \\
\hline & & Mean & StDev & Mean & StDev & & \\
\hline Arrowheads & 118 & 15.09 & 3.93 & 4.13 & 1.29 & Bifacial Rhomboid & Thomas 1978 [49] \\
\hline Dart-tips & 40 & 23.05 & 4.45 & 4.96 & 1 & Bifacial Rhomboid & $\begin{array}{l}\text { Thomas } 1978 \text { [49]; } \\
\text { Shott } 1997[50]\end{array}$ \\
\hline KRM MSA I: Triangular flakes & 71 & 33.61 & 6.04 & 9.82 & 2.17 & Unifacial Triangular & S. Wurz \\
\hline KRM MSA II Lower: Triangular flakes & 528 & 35 & 7.85 & 11.96 & 3.87 & Unifacial Triangular & S. Wurz \\
\hline KRM MSA II Upper: Triangular flakes & 298 & 31.77 & 7.17 & 10.93 & 2.95 & Unifacial Triangular & S. Wurz \\
\hline South African Stillbay points & 203 & 27 & 7.8 & 9.94 & 3.83 & Bifacial Rhomboid & T. Minichillo \\
\hline Blombos Cave Stillbay points & 239 & 26.56 & 9.77 & 9.53 & 4.46 & Bifacial Rhomboid & M. Soressi \\
\hline Porc Epic Bifacial Points & 94 & 23.61 & 5.82 & 8.36 & 2.66 & Bifacial Rhomboid & D. Pleurdeau \\
\hline Porc Epic Unifacial Points & 306 & 23.15 & 5.6 & 7.45 & 2.22 & Unifacial Triangular & D. Pleurdeau \\
\hline Aterian tanged points: Aoulef & 4 & 26 & 3.56 & 6.13 & 1.32 & Unifacial Triangular & T. Tillet; J. Shea \\
\hline Aterian tanged points: Asriouel & 46 & 26.26 & 5.33 & 7.65 & 1.86 & Unifacial Triangular & T. Tillet; J. Shea \\
\hline Aterian tanged points: Azrag & 18 & 24.17 & 5.09 & 6.83 & 1.76 & Unifacial Triangular & T. Tillet; J. Shea \\
\hline Aterian tanged points: Izouzaden & 12 & 31.92 & 5.84 & 10.58 & 1.62 & Unifacial Triangular & T. Tillet; J. Shea \\
\hline Aterian tanged points: Bir El Ater & 41 & 29.63 & 8.19 & 8.17 & 1.7 & Unifacial Triangular & Peabody Museum; J. Shea \\
\hline All Aterian tanged points & 124 & 27.65 & 6.78 & 7.95 & 2.01 & Unifacial Triangular & - \\
\hline
\end{tabular}

TABle 2: African MSA samples compared to ethnographic arrowheads and dart tips by independent sample $t$-tests. ${ }^{*} p<.05 ; * * p<.01$; ${ }^{* * *} p<.001$; n.s.: the two samples cannot be distinguished with $95 \%$ confidence; var: point estimated with the triangular measure, but using the rhomboid measure changes the result.

\begin{tabular}{|c|c|c|c|c|c|c|c|}
\hline \multirow{2}{*}{ Industry } & \multirow{2}{*}{$N$} & \multirow{2}{*}{ Mean TCSA } & \multirow{2}{*}{ Mean TCSP } & \multicolumn{2}{|c|}{ Versus arrowheads } & \multicolumn{2}{|c|}{ Versus dart tips } \\
\hline & & & & TCSA & TCSP & TCSA & TCSP \\
\hline KRM MSA I: triangular flakes & 71 & 167.98 & 72.68 & $* * *$ & $* * *$ & $* * *$ & $* * *$ \\
\hline KRM MSA II lower: triangular flakes & 528 & 216.77 & 77.66 & $* * *$ & $* * *$ & $* * *$ & $* * *$ \\
\hline KRM MSA II upper: triangular flakes & 298 & 180.33 & 70.51 & $* * *$ & $* * *$ & $* * *$ & $* * *$ \\
\hline South African Stillbay points & 203 & 144.64 & 57.73 & $* * *$ & $* * *$ & $* * *$ & $* * *$ \\
\hline Blombos Cave Stillbay points & 239 & 142.85 & 56.65 & $* * *$ & $* * *$ & $* * *$ & $* * *$ \\
\hline Porc Epic bifacial points & 94 & 103.29 & 50.25 & $* * *$ & $* * *$ & $* * *$ & n.s. \\
\hline Porc Epic unifacial points & 306 & 88.43 & 50.93 & $* * *$ & $* * *$ & $* * *$ & $\begin{array}{l}* \\
\text { var }\end{array}$ \\
\hline Aterian tanged points: Aoulef & 4 & 81.13 & 54.76 & $* * *$ & $* * *$ & * & n.s. \\
\hline Aterian tanged points: Asriouel & 46 & 103.46 & 56.76 & $* * *$ & $* * *$ & $* * *$ & $* * *$ \\
\hline Aterian tanged points: Azrag & 18 & 85.28 & 52.02 & $* * *$ & $* * *$ & $* *$ & n.s. \\
\hline Aterian tanged points: Izouzaden & 12 & 170.83 & 70.33 & $* * *$ & $* * *$ & $* * *$ & $* * *$ \\
\hline Aterian tanged points: Bir El Ater & 41 & 124.28 & 63.66 & $* * *$ & $* * *$ & $* * *$ & $* * *$ \\
\hline All Aterian tanged points & 124 & 116.38 & 60.02 & $* * *$ & $* * *$ & $* * *$ & $* * *$ \\
\hline
\end{tabular}

that Aterian points (which are typologically defined by a tang or shoulder) were not always used for the same purpose. These larger points may have been used differently, possibly as multipurpose tools (e.g., [51]) and/or as armatures for larger thrusting or hand-cast spears.

This is also true for the two samples of Stillbay points. Even with the largest examples removed, the TCSA of these two samples significantly exceeds that of the ethnographic complex projectile points [23]. When the full samples are analyzed with TCSP they remain significantly larger than ethnographic dart tips, but the box and whisker plot reveals large overlapping areas with the ethnographic dart tips. As has been noted previously, Stillbay points vary widely in size [52]. This may then be a case of one technological style being 


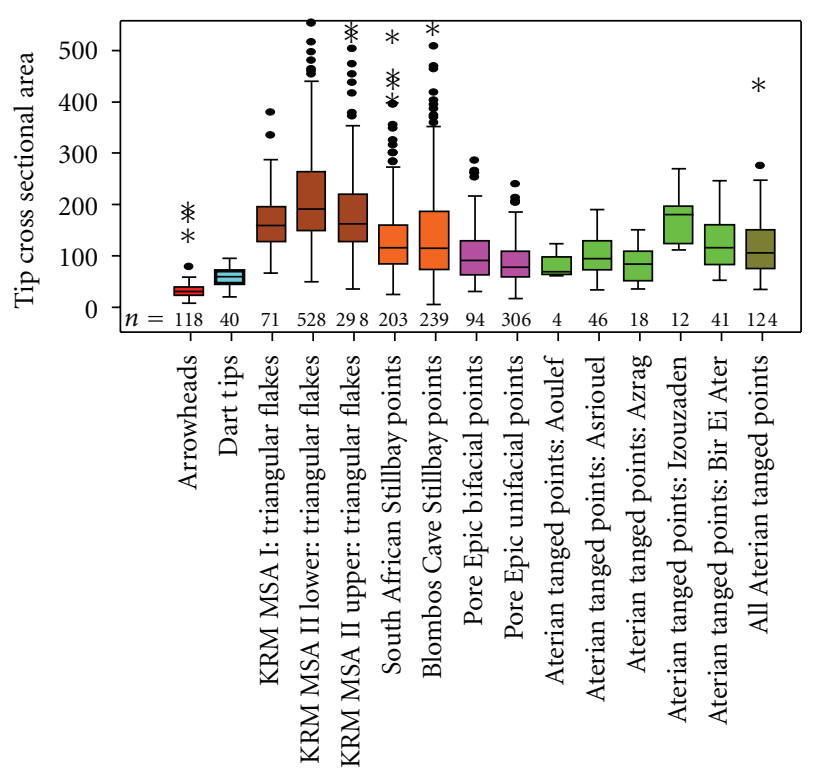

Figure 3: Box and whisker plot of TCSA values for ethnographic controls and each sample of MSA points. The area between the upper and lower quartile for the controls is highlighted to show overlap with the MSA points.

used to create tools for a variety of uses. Thus, while there is no statistical support for the Klasies River Mouth or Blombos Stillbay points falling within the variation of ethnographic projectiles, the overlap of the smaller examples is intriguing and merits further study.

The triangular flakes from Klasies River Mouth are significantly larger than the comparative samples in both TCSA and TCSP. As noted by Shea [23] these triangular flakes are a broad typological category and likely represent a variety of different things. These triangular flakes are among the largest and most variable used in this or in Shea's [23] study (Table 1). In this case, a lack of overlap could potentially represent a large, highly variable, type with a small sample of projectile points contained within. More likely, though, it simply reflects archaeologists' longstanding habit of lumping together into the same tool type artifacts of widely-variable size.

The strongest case for plausible complex projectile use in the MSA comes from the two collections from Porc Epic. The overlap between the Porc Epic points, both unifacial and bifacial, and ethnographic dart tips shows that these points were created in response to particular morphological constraints. Currently, there is a better indication of plausible projectile use for the bifacially worked pieces, but sample size may play a role here $(n=94$ for bifacial points versus $n=306$ unifacial points). Both of these samples are larger than the ethnographic dart-tip sample. Thus it is possible that the ethnographic controls themselves do not fully capture the variability in complex projectile point morphology. The Porc Epic samples are conservatively dated to between 60 and $70 \mathrm{ka}$ [53], only slightly earlier than the older estimated dates of permanent dispersal of Homo sapiens out of Africa.

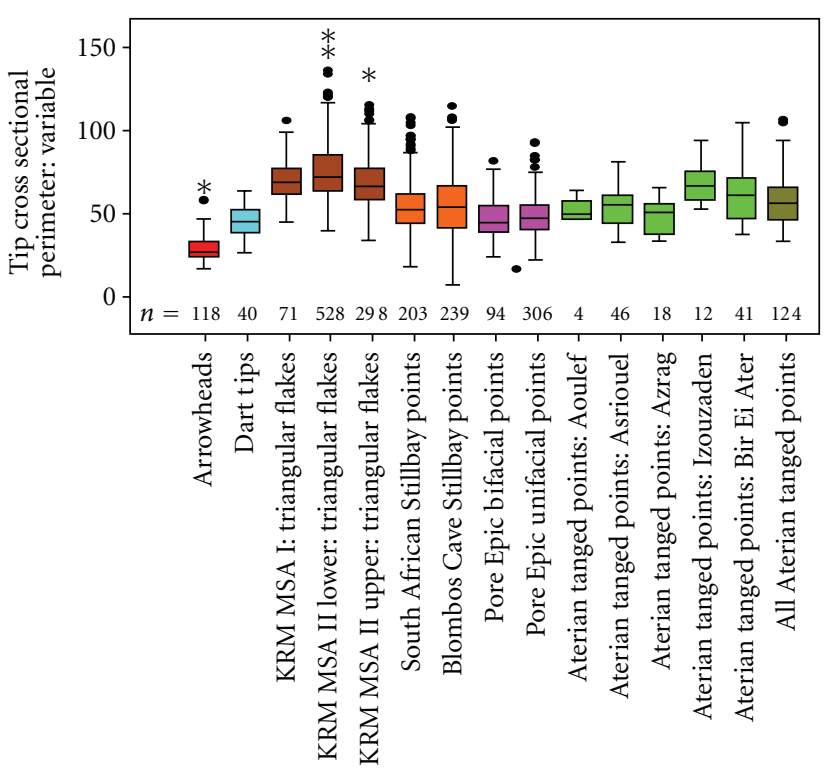

FIGURE 4: Box and whisker plot of TCSP values for ethnographic controls and each sample of MSA points. The area between the upper and lower quartile for the controls is highlighted to show overlap with the MSA points.

These data provide compelling indications of complex projectile usage in the MSA, but it is important to reiterate that these relationships only show plausibility. The metric properties of stone points from Porc Epic, and the other samples discussed above, are not irrefutable evidence for the presence of complex projectiles in the MSA. Nevertheless, they do indicate that many of these tools could have been effective armatures for complex projectile weapons. Conclusive proof for the antiquity of complex projectile weapons in Africa will depend on confirmation or refutation from independent lines of evidence such as microwear, residue analysis, and zooarchaeological studies of MSA predation strategies.

\section{Conclusions}

Although it is a more complex measure relying on an estimation of the cross-sectional geometry, TCSP is a more accurate measure of plausible projectile usage than TCSA. By using TCSP, we were able to isolate significant relationships in the African MSA that were hidden in the TCSA data. In actuality, it is likely the interplay of TCSA and TCSP that predicts projectile effectiveness. A point that maximizes perimeter at the expense of area would be so thin and so fragile as to be useless. The inverse, a point that maximizes area at the expense of perimeter, may not function as an effective armature. Further models should analyze both these measures, as area remains an important predictor of durability [54], while perimeter controls actual penetration effectiveness.

Additionally, the methodology for TCSP used here only works for points. Unfortunately, some of the best candidates for early projectiles in Africa are backed pieces [55]. If these 
objects were hafted as projectile armatures they would not resemble the ethnographic points used in this study. Alternative measurements and comparative samples are needed for backed pieces, and such investigations are currently underway by several research teams (e.g., $[17,46,48,56])$.

The data presented in this paper demonstrate that plausible projectile armatures are present in several tool types of the Middle Stone Age and more are likely hidden in the variability encompassed by typological classifications. The current project demonstrates both the complexity of analyzing potential projectile use from a restricted sample and the possibility of refining these techniques. From these analyses, it seems apparent that the use of complex projectiles has its origins in the African MSA. Populations armed with complex projectiles are more ecologically versatile and can access a broader niche than those without them. Thus, the development of this technology was an important component of the adaptive change in Homo sapiens populations that allowed the successful colonization of the Old World at $50 \mathrm{ka}$. Complex projectiles are, however, not the only component of this behavioral transformation. It is only through continued collaborative analysis, experimentation, and interpretation that we can compile these data into a full picture of these technologies and how they contributed to the evolutionary success of Homo sapiens.

\section{Acknowledgments}

The authors are grateful to the researchers who kindly provided metric data to J. J. Shea (for this project including S. Wurz, T. Minichillo, M. Soressi, and T. Tillet). Ian Wallace and Jennifer Henecke provided invaluable comments on an earlier draft. Initial funding for the experimental collection was provided by a Wenner-Grenn Foundation for Anthropological Research grant to J. J. Shea.

\section{References}

[1] J. G. Fleagle, Z. Assefa, F. H. Brown, and J. J. Shea, "Paleoanthropology of the Kibish formation, southern Ethiopia: introduction," Journal of Human Evolution, vol. 55, no. 3, pp. 360-365, 2008.

[2] P. Soares, L. Ermini, N. Thomson et al., "Correcting for purifying selection: an improved human mitochondrial molecular clock," American Journal of Human Genetics, vol. 84, no. 6, pp. 740-759, 2009.

[3] J. J. Shea and O. Bar-Yosef, "Who were the Skhul/Qafzeh people?: an archaeological perspective on Eurasia's earliest modern humans," Journal of the Israel Prehistoric Society, vol. 35, pp. 449-466, 2005.

[4] R. G. Klein, "Out of Africa and the evolution of human behavior," Evolutionary Anthropology, vol. 17, no. 6, pp. 267281, 2008.

[5] E. Trinkaus, "Early modern humans," Annual Review of Anthropology, vol. 34, pp. 207-230, 2005.

[6] P. A. Mellars, K. Boyle, O. Bar-Yosef, and C. B. Stringer, Rethinking the human revolution: new behavioural and biological perspectives on the origin and dispersal of modern humans, McDonald Institute for Archaeological Research Monographs, Cambridge, UK, 2007.
[7] J. F. O'Connell and J. Allen, "Pre-LGM Sahul (Pleistocene Australia-New Guinea) and the archaeology of early modern humans," in Rethinking the Human Revolution: New Behavioural and Biological Perspectives on the Origin and Dispersal of Modern Humans, P. A. Mellars, K. Boyle, O. Bar-Yosef, and C. B. Stringer, Eds., pp. 395-410, McDonald Institute for Archaeological Research Monographs, Cambridge, UK, 2007.

[8] R. W. Dennell, The Palaeolithic Settlement of Asia, Cambridge University Press, Cambridge, UK, 2009.

[9] P. Endicott, S. Y. W. Ho, and C. Stringer, "Using genetic evidence to evaluate four palaeoanthropological hypotheses for the timing of Neanderthal and modern human origins," Journal of Human Evolution, vol. 59, no. 1, pp. 87-95, 2010.

[10] N. Maca-Meyer, A. M. González, J. M. Larruga, C. Flores, and V. M. Cabrera, "Major genomic mitochondrial lineages delineate early human expansions," BMC Genetics, vol. 2, no. 1, article 13, 2001.

[11] S. Mcbrearty and A. S. Brooks, "The revolution that wasn't: a new interpretation of the origin of modern human behavior," Journal of Human Evolution, vol. 39, no. 5, pp. 453-563, 2000.

[12] P. A. Mellars, "Rethinking the human revolution: Eurasian and African perspectives," in New Behavioural and Biological Perspectives on the Origin and Dispersal of Modern Humans, P. A. Mellars, K. Boyle, O. Bar-Yosef, and C. B. Stringer, Eds., pp. 1-14, McDonald Institute for Archaeological Research Monographs, Cambridge, UK, 2007.

[13] P. R. Willoughby, The Evolution of Modern Humans in Africa: A Comprehensive Guide, Altamira, New York, NY, USA, 2007.

[14] C. Finlayson, The Humans Who Went Extinct: Why Neanderthals Died Out and We Survived, Oxford University Press, Oxford, UK, 2009.

[15] C. S. Henshilwood and C. W. Marean, "The origin of modern human behavior: critique of the models and their test implications," Current Anthropology, vol. 44, no. 5, pp. 627651, 2003.

[16] S. L. Kuhn and M. C. Stiner, "What's a mother to do? The division of labor among Neandertals and modern humans in Eurasia," Current Anthropology, vol. 47, no. 6, pp. 953-980, 2006.

[17] J. J. Shea, "The impact of projectile weaponry on late Pleistocene hominin evolution," in The Evolution of Hominin Diets, J. Hublin and M. P. Richards, Eds., pp. 189-199, Springer, New York, NY, USA, 2009.

[18] J. J. Shea and M. L. Sisk, "Projectile technology and homo sapiens dispersal from Africa to Western Eurasia," PaleoAnthropology, vol. 2010, pp. 100-122, 2010.

[19] M. L. Sisk and J. J. Shea, "Defining complex projectile technology: a reply to Whittaker," PaleoAnthropology, vol. 2010, pp. L08-L09, 2010.

[20] S. E. Churchill, "Weapon technology, prey size selection and hunting methods in modern hunter-gatherers: implications for hunting in the Palaeolithic and Mesolithic," in Hunting and Animal Exploitation in the Later Palaeolithic and Mesolithic of Eurasia, Archeological Papers of the American Anthropological Association, G. L. Peterkin, H. M. Bricker, and P. A. Mellars, Eds., Archeological Papers of the American Anthropological Association, no. 4, pp. 11-24, American Anthropological Association, Washington, DC, USA, 1993.

[21] P. Yu, "From atlatl to bow and arrow: implicating projectile technology in changing systems of hunter-gatherer mobility," in Projectile Technology in Changing Systems of HunterGatherer Mobility, F. Sellet, R. Greaves, and P. Yu, Eds., University Press of Florida, Gainesville, Fla, USA, 2006. 
[22] H. Knecht, Projectile Technology, Plenum, New York, NY, USA, 1997.

[23] J. J. Shea, "The origins of lithic projectile point technology: evidence from Africa, the Levant, and Europe," Journal of Archaeological Science, vol. 33, no. 6, pp. 823-846, 2006.

[24] H. Thieme, "Lower palaeolithic hunting spears from Germany," Nature, vol. 385, no. 6619, pp. 807-810, 1997.

[25] H. Thieme, "Lower Paleolithic hunting weapons from Schöningen, Germany: the oldest spears in the world," Acta Anthropologica Sinica, vol. 19, pp. 136-143, 2000.

[26] P. Cattelain, "Hunting during the Upper Paleolithic: bow, spearthrower, or both?" in Projectile Technology, H. Knecht, Ed., pp. 213-240, Plenum, New York, NY, USA, 1997.

[27] J. J. Shea, "Spear points from the Middle Paleolithic of the levant," Journal of Field Archaeology, vol. 15, pp. 441-450, 1988.

[28] R. E. Donahue, M. L. Murphy, and L. Robbins, "Lithic microwear analysis of Middle Stone Age artifacts from White Paintings Rock Shelter, Botswana," Journal of Field Archaeology, vol. 29, pp. 155-163, 2002.

[29] M. Lombard, "A method for identifying stone age hunting tools," South African Archaeological Bulletin, vol. 60, no. 182, pp. 115-120, 2005.

[30] M. Lombard, "Evidence for change in Middle Stone Age hunting behaviour at Blombos Cave: results of a macrofracture analysis," South African Archaeological Bulletin, vol. 62, no. 185, pp. 62-67, 2007.

[31] J. J. Shea, "Middle Paleolithic spear point technology," in Projectile Technology, H. Knecht, Ed., pp. 79-106, Plenum, New York, NY, USA, 1997.

[32] S. L. Kuhn and M. C. Stiner, "The antiquity of huntergatherers," in Hunter-gatherers: Interdisciplinary Perspectives, C. Panter-Brick, R. H. Layton, and P. A. Rowley-Conwy, Eds., pp. 99-142, Cambridge University Press, Cambridge, UK, 2001.

[33] P. Wiessner, "Style and social information in Kalahari San projectile points," American Antiquity, vol. 48, pp. 253-276, 1983.

[34] J. J. Flenniken, "Stone tool reduction techniques as cultural markers," in Stone Tool Analysis: Essays in Honor of Don E. Crabtree, M. G. Plew, J. C. Woods, and M. G. Pavesic, Eds., pp. 265-276, University of New Mexico Press, Albuquerque, NM, USA, 1985.

[35] K. M. Ames, K. A. Fuld, and S. Davis, "Dart and arrow points on the Columbia Plateau of Western North America," American Antiquity, vol. 75, no. 2, pp. 287-325, 2010.

[36] R. L. Bettinger, J. F. O'Connell, and D. H. Thomas, “Projectile points as time markers in the Great Basin," American Anthropologist, vol. 93, pp. 166-172, 1991.

[37] J. Flenniken and P. Wilke, "Typology, technology, and chronology of Great Basin dart points," American Anthropologist, vol. 91, pp. 149-158, 1989.

[38] P. J. Wilke and J. J. Flenniken, "Missing the point-rebuttal," American Anthropologist, vol. 93, pp. 172-173, 1991.

[39] G. H. Odell and F. Cowan, "Experiments with spears and arrows on animal targets," Journal of Field Archaeology, vol. 13, pp. 194-212, 1986.

[40] M. L. Sisk and J. J. Shea, "Experimental use and quantitative performance analysis of triangular flakes (Levallois points) used as arrowheads," Journal of Archaeological Science, vol. 36, no. 9, pp. 2039-2047, 2009.

[41] V. Waweru, Middle Stone Age Archaeology of the Cartwright's Site, Kenya, University of Connecticut, Storrs, Conn, USA, 2007.
[42] N. M. Waguespack, T. A. Surovell, A. Denoyer et al., "Making a point: wood-versus stone-tipped projectiles," Antiquity, vol. 83, no. 321, pp. 786-800, 2009.

[43] A. S. Brooks, J. E. Yellen, L. Nevell, and G. Hartman, "Projectile technologies of the African MSA: implications for modern human origins," in Transitions Before the Transition, E. Hovers and S. L. Kuhn, Eds., pp. 233-255, Springer, New York, NY, USA, 2006.

[44] P. Villa, P. Boscato, F. Ranaldo, and A. Ronchitelli, "Stone tools for the hunt: points with impact scars from a Middle Paleolithic site in southern Italy," Journal of Archaeological Science, vol. 36, no. 3, pp. 850-859, 2009.

[45] J. Shea, Z. Davis, and K. Brown, "Experimental tests of middle palaeolithic spear points using a calibrated crossbow," Journal of Archaeological Science, vol. 28, no. 8, pp. 807-816, 2001.

[46] M. Lombard and J. Pargeter, "Hunting with Howiesons Poort segments: pilot experimental study and the functional interpretation of archaeological tools," Journal of Archaeological Science, vol. 35, no. 9, pp. 2523-2531, 2008.

[47] S. S. Hughes, "Getting to the point: evolutionary change in prehistoric weaponry," Journal of Archaeological Method and Theory, vol. 5, no. 4, pp. 345-408, 1998.

[48] F. Riede, "The loss and re-introduction of bow-and-arrow technology: a case study from the Southern Scandinavian Late Palaeolithic," Lithic Technology, vol. 34, pp. 27-45, 2009.

[49] D. H. Thomas, "Arrowheads and atlatl darts—how stones got shaft," American Antiquity, vol. 43, pp. 461-472, 1978.

[50] M. J. Shott, "Stones and shafts redux: the metric discrimination of chipped-stone dart and arrow points," American Antiquity, vol. 62, no. 1, pp. 86-101, 1997.

[51] R. Greaves, "Hunting and multifunctional use of bows and arrows: ethnoarchaeology of technological organization among the Pumé hunters of Venezuela," in Projectile Technology, H. Knecht, Ed., pp. 287-320, Plenum, New York, NY, USA, 1997.

[52] T. Minichillo, Middle Stone Age lithic study, South Africa: an examination of modern human origins, Ph.D. dissertation, University of Washington, 2005.

[53] J. D. Clark, K. D. Williamson, J. W. Michels, and C. A. Marean, "A middle stone age occupation site at Porc Epic Cave, Dire Dawa (east-central Ethiopia), part II," The African Archaeological Review, vol. 2, no. 1, pp. 37-71, 1984.

[54] J. Cheshier and R. L. Kelly, "Projectile point shape and durability: the effect of thickness:Length," American Antiquity, vol. 71, no. 2, pp. 353-363, 2006.

[55] M. Lombard and L. Phillipson, "Indications of bow and stonetipped arrow use 64000 years ago in KwaZulu-Natal, South Africa," Antiquity, vol. 84, no. 325, pp. 635-648, 2010.

[56] A. Yaroshevich, D. Kaufman, D. Nuzhnyy, O. Bar-Yosef, and M. Weinstein-Evron, "Design and performance of microlith implemented projectiles during the Middle and the Late Epipaleolithic of the Levant: experimental and archaeological evidence," Journal of Archaeological Science, vol. 37, no. 2, pp. 368-388, 2010. 

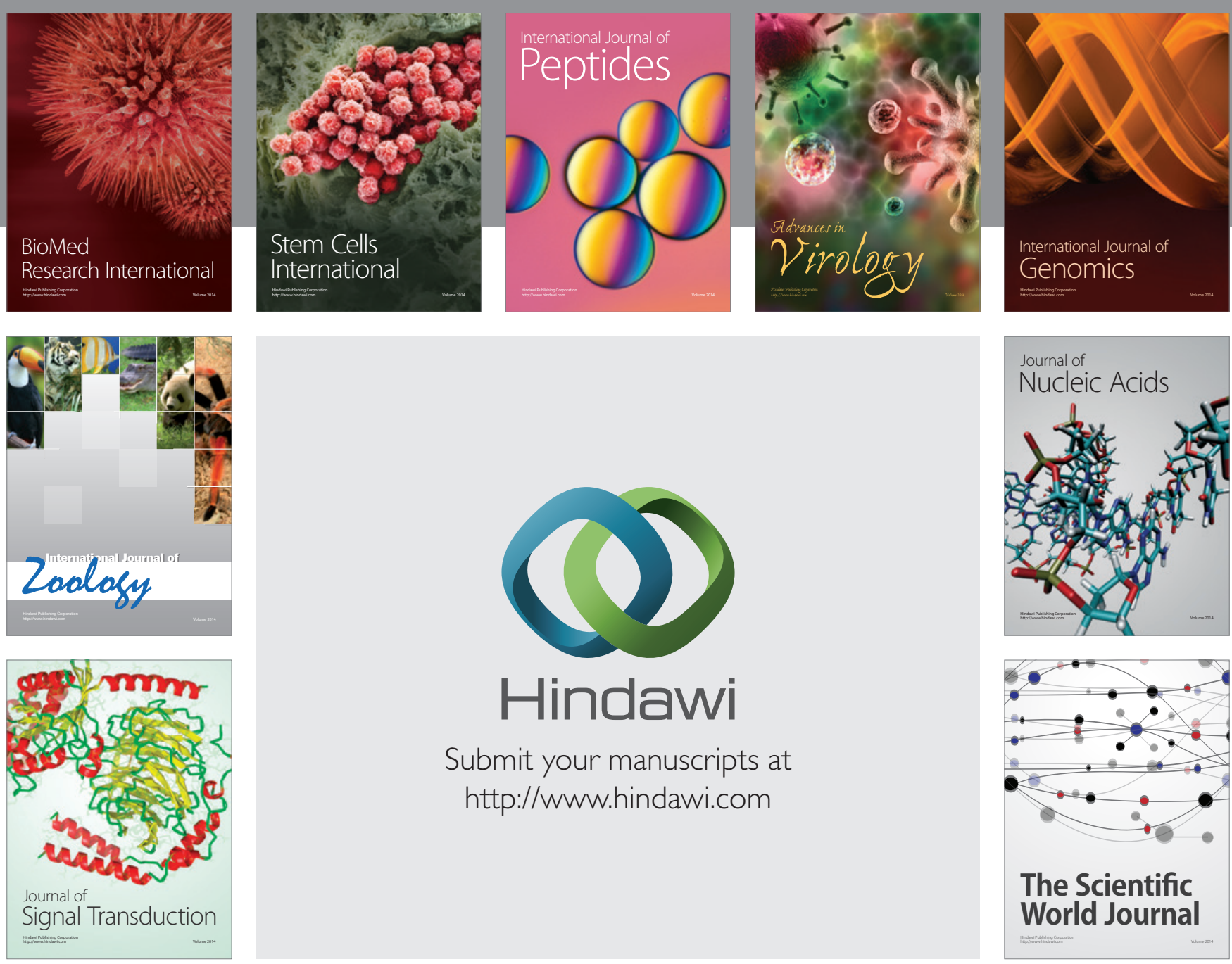

Submit your manuscripts at

http://www.hindawi.com
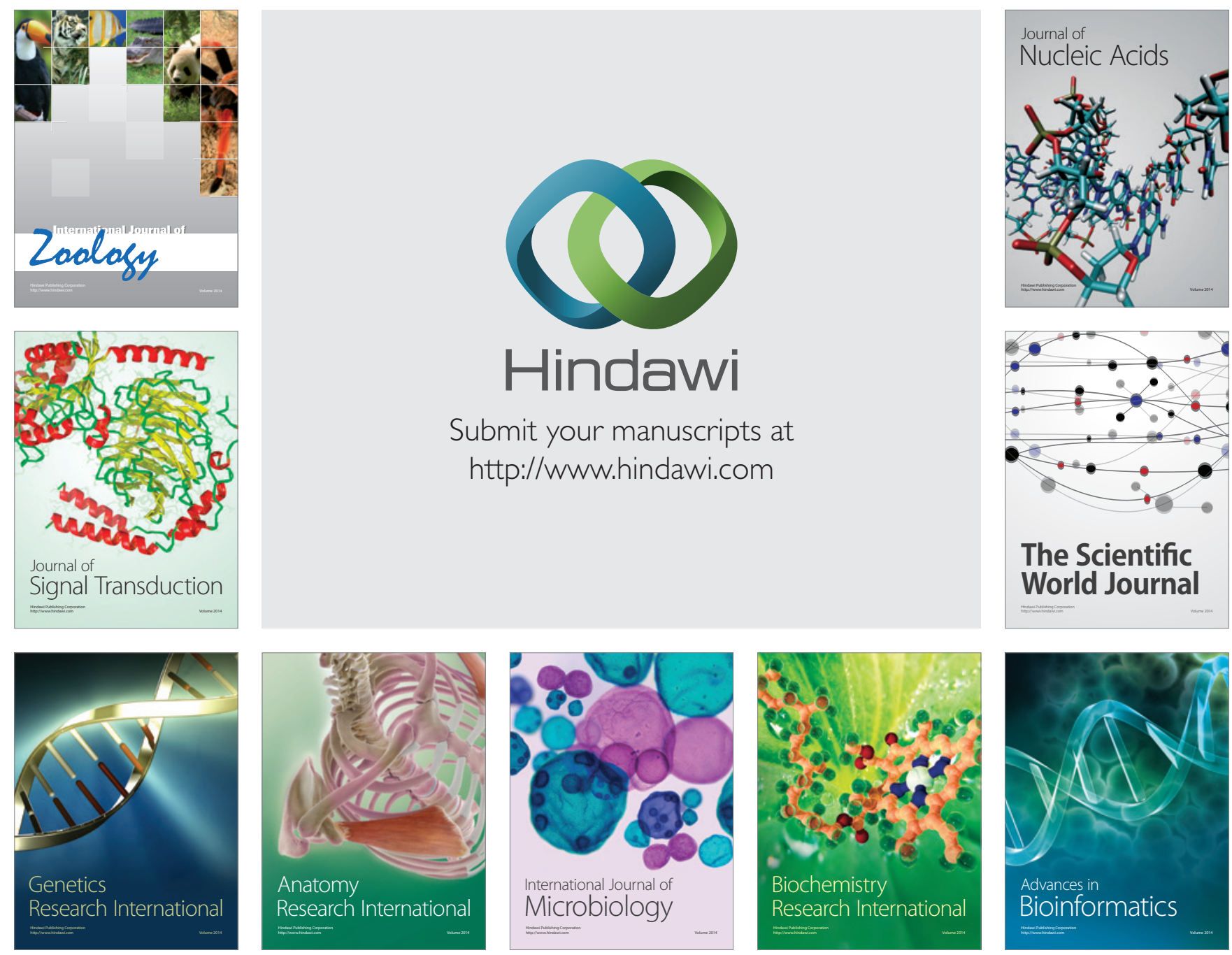

The Scientific World Journal
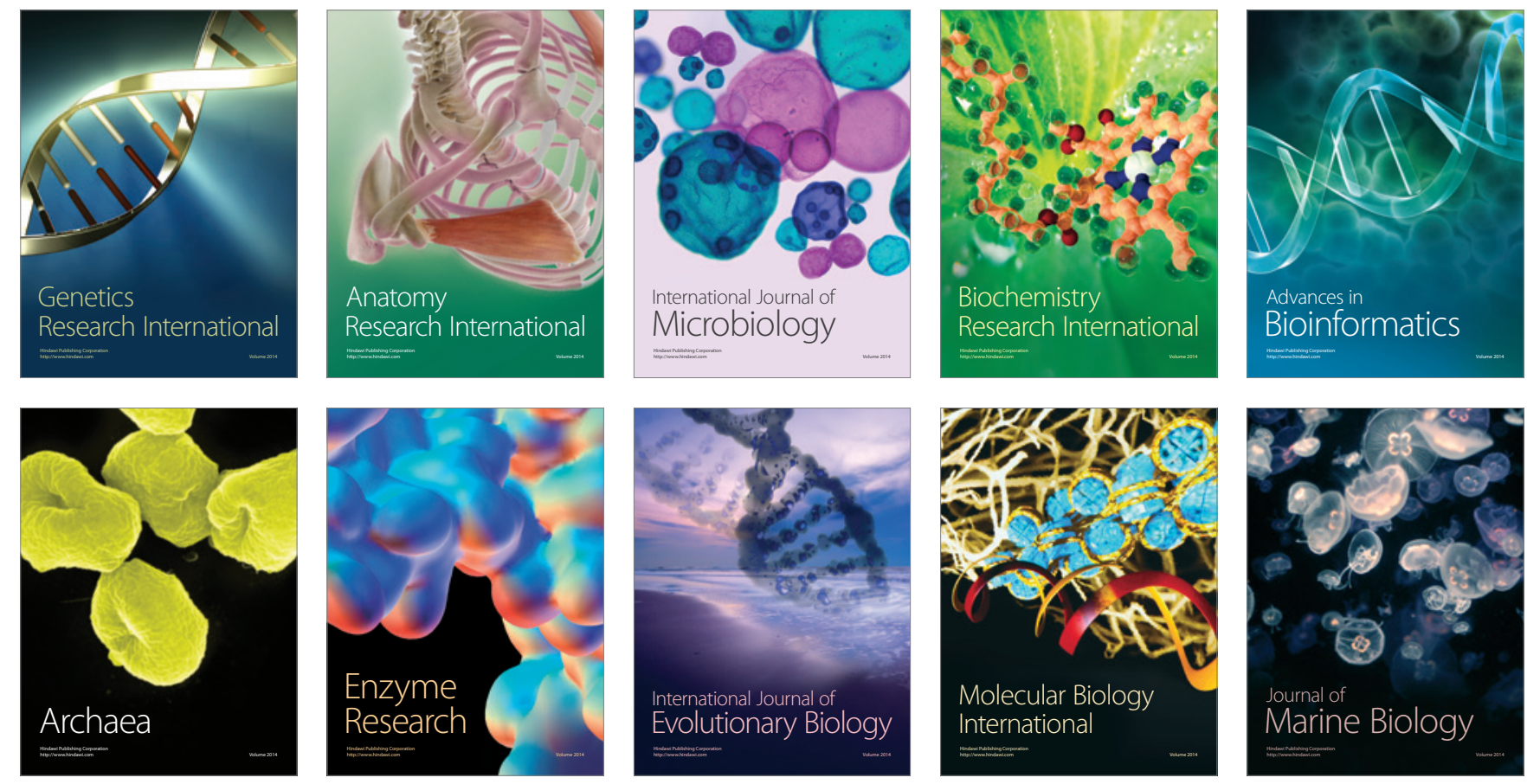